\title{
EVOLUTION IN CLOSELY ADJACENT PLANT POPULATIONS
}

\author{
VIII. CLINAL PATTERNS AT A MINE BOUNDARY \\ JANIS ANTONOVICS * \\ Department of Biology, University of Stirling \\ and
}

A. D. BRADSHAW

Department of Botany, University of Liverpool

Received 28.vi.69

\section{INTRODUCTION}

Several previous papers in this series have been concerned with the evolution of differences between tolerant and non-tolerant populations of grasses growing over the boundaries of mine tip and pasture soils (Jain and Bradshaw, 1966, McNeilly and Antonovics, 1968, Antonovics, 1968a). Metal tolerant plants differ both physiologically and morphologically from normal plants in several features other than tolerance. Differences in calcium and phosphate response are recorded by Jowett (1959) and McNeilly (1966); Turner (1967) has shown differences in sulphur response; and Schwanitz and Hahn (1954a, 1954b) showed from a study of a range of plant species grown under standard conditions that in general tolerant plants had smaller flowers, smaller leaves and thinner stems. This was confirmed for Silene inflata by Broker (1963) who concluded from segregating progenies that dwarfness was not linked to tolerance and had probably been selected independently. Similarly, morphological differences have been recorded in the grass Agrostis tenuis on lead mines (Bradshaw, 1959; Jowett, 1964) and copper mines (McNeilly, 1966).

The morphological characters of plants of the grass Anthoxanthum odoratum L. taken from sites along a transect across a mine/pasture boundary were investigated with three main points in view.

\section{(i) Clinal Patterns}

If selection for morphological characters is indeed independent of selection for tolerance, then the intensity of selection is likely to be different for different characters. This should lead to clines varying in their steepness.

\section{(ii) Character Correlations}

Strong selection for tolerance in mine populations (McNeilly, 1968) is analogous to strong selection pressure used in artificial experiments. Artificial selection for one character frequently leads to changes in other characters (e.g. Mather and Harrison, 1949; Cooper, 1960) and it was considered possible that such processes may be occurring on mine populations.

\section{(iii) Population Variability}

The evolution of tolerance allows colonisation of an open habitat and an increase in numbers of plants in that habitat. Ford (1964, p. 11) has

\footnotetext{
* Present address: Botany Department, Duke University, Durham, N. Carolina, U.S.A.
} 
argued on the basis of earlier investigations (Ford and Ford, 1930) that in an expanding population selection is relaxed and that this permits the survival of numerous variants. The situation on metal mines provides a model to test if there is increased variability in characters as a result of colonisation of a new habitat.

The variation of the plants along the transect with regard to various morphological characters was analysed by partitioning the overall variance into that due to differences between individuals within sites, and between sites within populations. In this way, it was possible to assess which differences contributed to the overall variation of the plants along the transect.

\section{METHODS}

Ten plants of Anthoxanthum odoratum L. were taken from each of eight sites on a transect about 100 metres long across the boundary between mine and pasture soils, at the Trelogan lead and zinc mine, Flintshire. The transect has been fully described by McNeilly and Antonovics (1968). The plants were collected in November 1963, grown in pots in the greenhouse and transplanted to fresh John Innes No. 1 compost for two months before field planting in August 1965. They had therefore been growing under comparable conditions for almost two years previous to the experiment.

Three tillers of each plant were then planted in the experimental garden at 9 inch spacing. There were four blocks, with eight sites randomised within each block, ten genotypes randomised within each site, and two individuals per genotype.

The following characters were measured in the following summer.

1. Metal (zinc) tolerance.

2. Flowering time (see McNeilly and Antonovics, 1968). Only date of stigma emergence is shown here.

3. Self-fertility (see Antonovics, 1968a). Data subjected to log transformation before analysis of variance.

4. Plant height (on 25.6.66).

5. Mean culm length (on 3.8.66). Distance from inflorescence tip to first internode on 30 inflorescences taken at random.

6. Flag leaf length (on 3.6.66). Average length of eight leaves taken at random.

7. Flag leaf width (on 3.6.66). Average width of eight leaves taken at random.

8. Total tiller number (on 1.8.66).

9. Flowering tiller number (on 1.8.66).

10. Vegetative tiller number (on 1.8.66).

From these measurements the following additional parameters were calculated:

11. Proportion of vegetative to total tillers (vegetativeness). Data subjected to arcsin transformation before analysis of variance.

12. Coefficient of variation of flag leaf length within plant (eight leaves per plant).

13. Coefficient of variation of culm length within plant (thirty culms per plant). 


\section{(a) Results}

\section{Clinal patterns}

The clinal patterns obtained for each character are shown in fig. 1. The scales have been made comparable for different characters by ensuring that $(a)$ the positions of the sites along the horizontal axes are always to the same scale and $(b)$ the range between the smallest and largest average measures for different genotypes is always the same distance. It is seen that for some characters clear cut clines are evident (tolerance, flowering time, self fertility and plant height), for others there is a gradual clinal pattern (flag leaf length and culm length) while for a third group no clear cut clinal pattern emerges (flag leaf width, tiller number features, and coefficients of within plant variation).

This is reflected in the analyses of variance (table 1). In the group where there are steep clines there are on the whole large and significant differences between populations, yet small insignificant differences between sites within populations. In the group with gradual clines, the between population differences are just significant, but there are large between site within population differences. In the group with no clear cut pattern there are few differences between populations or between sites within populations. There, are, however, significant within site (between genotype) differences suggesting that the lack of clinal differentiation is not due to lack of genetic variability.

For some characters showing steep clines the intermediate site (No. 5) is like the pasture sites (tolerance, total tiller number) whereas with regard to other characters, it is more like the mine population (flowering time, selffertility and height).

\section{(b) Discussion}

The existence of different clinal patterns across the same ecological boundary can have several explanations.

Firstly, the characters maybe have a different genetic basis. The positior. of the cline at a boundary is determined by whether the character is dominant or recessive (Haldane, 1948), and the effects of gene flow are less severe on a favoured character if it is dominant (Antonovics, 1968b). This may therefore explain the slight differences in the positions of the different clines at the boundary (i.e. whether site 5 resembles cline sites or pasture sites) but should have little effect on the broad clinal pattern.

Secondly, the characters could be subjected to selection by different environmental parameters each of which changes in a specified way which matches the distribution of the character across the boundary. Kimura (1958) found that the distance over which a selective advantage changes can determine the steepness of a cline. However, it is unlikely that the various environmental factors would vary gradually or at different rates across the boundary. Metal content (Jain and Bradshaw, 1966) and soil moisture content (Antonovics, 1968a) vary abruptly and other differences probably show a similar pattern since they must be related to the sharp edaphic change at the mine boundary.

Thirdly, the selective pressures across the boundary may not match the distribution of the character but may all change sharply at the boundary. Since all the characters were measured on the same set of plants, gene flow 


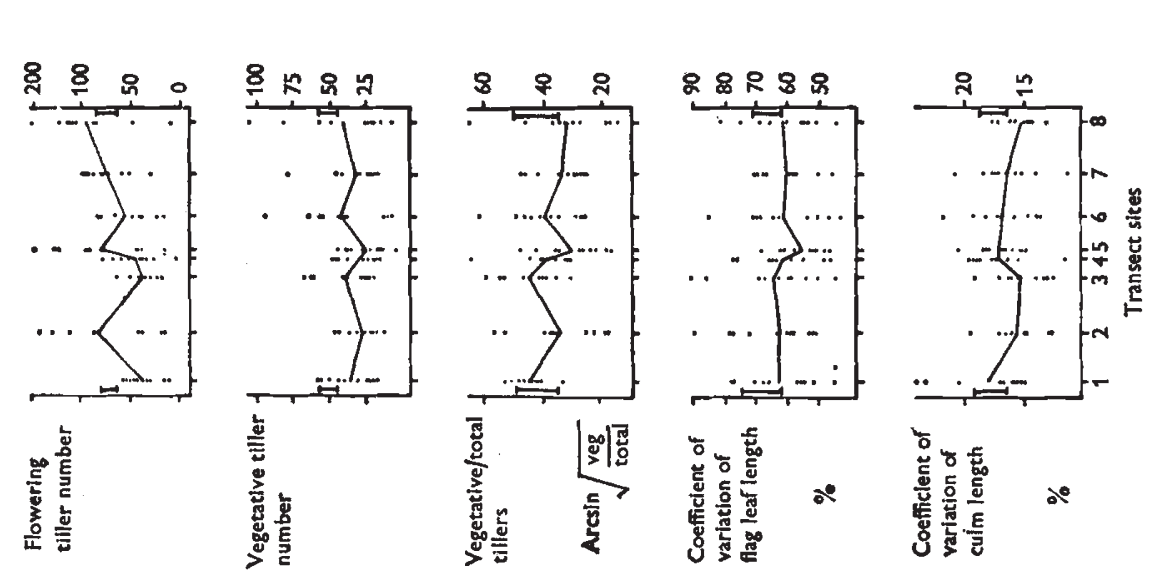

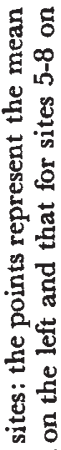

苑

总莺

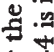

总

突

造

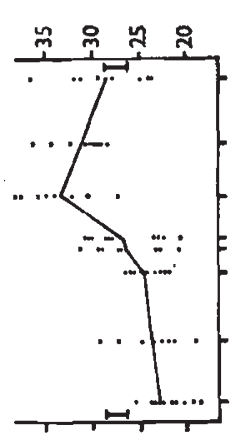

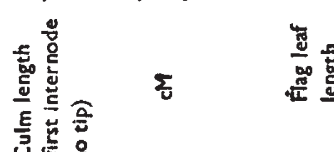
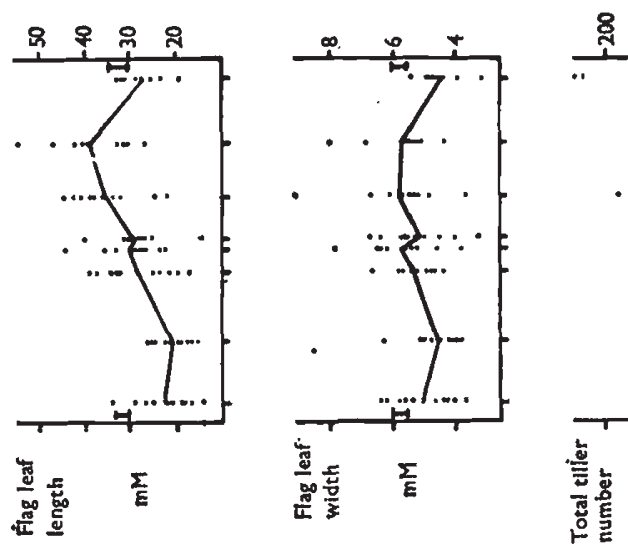

ษ

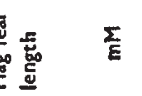


must have been equivalent for all the characters. The different clinal patterns may therefore be the result of differing selection pressures (but equal gene flow) across the boundary (Jain and Bradshaw, 1966). This seems the most likely explanation of the results and further emphasises the interplay of gene flow and selection at mine boundaries.

\section{TABLE 1}

Table showing significance of differences between tolerant and non-tolerant populations (sites 1-4 v 5-8), between sites, and between genotypes for different characters. Differences between genotypes were tested against the error mean square, between sites against the genotype mean square and between populations against the site mean square

Significance levels in analyses of variance

$\begin{array}{ccc}\begin{array}{c}\text { Between populations } \\ 1-4\end{array} \text { } 5-8 & \begin{array}{c}\text { Between sites } \\ \text { within populations }\end{array} & \begin{array}{c}\text { Between genotypes } \\ \text { within sites }\end{array}\end{array}$

Tolerance

Flowering time

Self fertility

Height

Culm length

Flag leaf length

Flag leaf width

Total tiller No.

Flowering tiller No.

Vegetative tiller No.

Veg/total tillers

Coeff. var. flag leaf length

Coeff. var. culm length

$$
\begin{aligned}
& \text { *** } \\
& \text { N.S. } \\
& \text { N.S.† } \\
& \text { ** } \\
& <10 \% \\
& \text { N.S. } \\
& <10 \% \\
& \text { N.S. } \\
& <10 \% \\
& \text { N.S. } \\
& \text { N.S. }
\end{aligned}
$$

$\begin{array}{lr}\text { N.S. } & - \\ \text { N.S. } & * * * \\ \text { N.S. } & * * * \\ * * * & * * * \\ * * * & * * * \\ * * & * * * \\ <10 \% & * * * \\ * * & * * * \\ \text { N.S. } & * * * \\ <10 \% & * * * \\ \text { N.S. } & * * * \\ \text { N.S. } & * * * \\ & \end{array}$

\$ Flowering time: between populations $1-5 v 6-7, * * *$.

$\dagger$ Self fertility: between populations $1-5 v 6-8 * *$.

Haldane (1948) has suggested a method for calculating the selection pressure from the steepness of a cline, using the formula:

$$
\begin{aligned}
K & \simeq \frac{m^{2}}{2 d^{2}} \\
\text { where } K & =\text { selection pressure, } \\
m & =\text { mean distance of gene dispersal, } \\
d & =\text { interquartile distance. }
\end{aligned}
$$

The mean distance of gene flow at the Trelogan boundary is not known but several previous estimates are available.

(i) 8.2 feet (calculated from data of Griffiths, 1952, using Lolium perenne).

(ii) 7-11 feet (McNeilly, 1966, using Pine and Lycopodium pollen).

(iii) 11.3-14.2 feet (unpublished data, using Pine and Lycopodium pollen).

All these values give a mean dispersal distance of the order of 10 feet. Since the interquartile distances can be estimated from the clinical pattern, it is 
莡

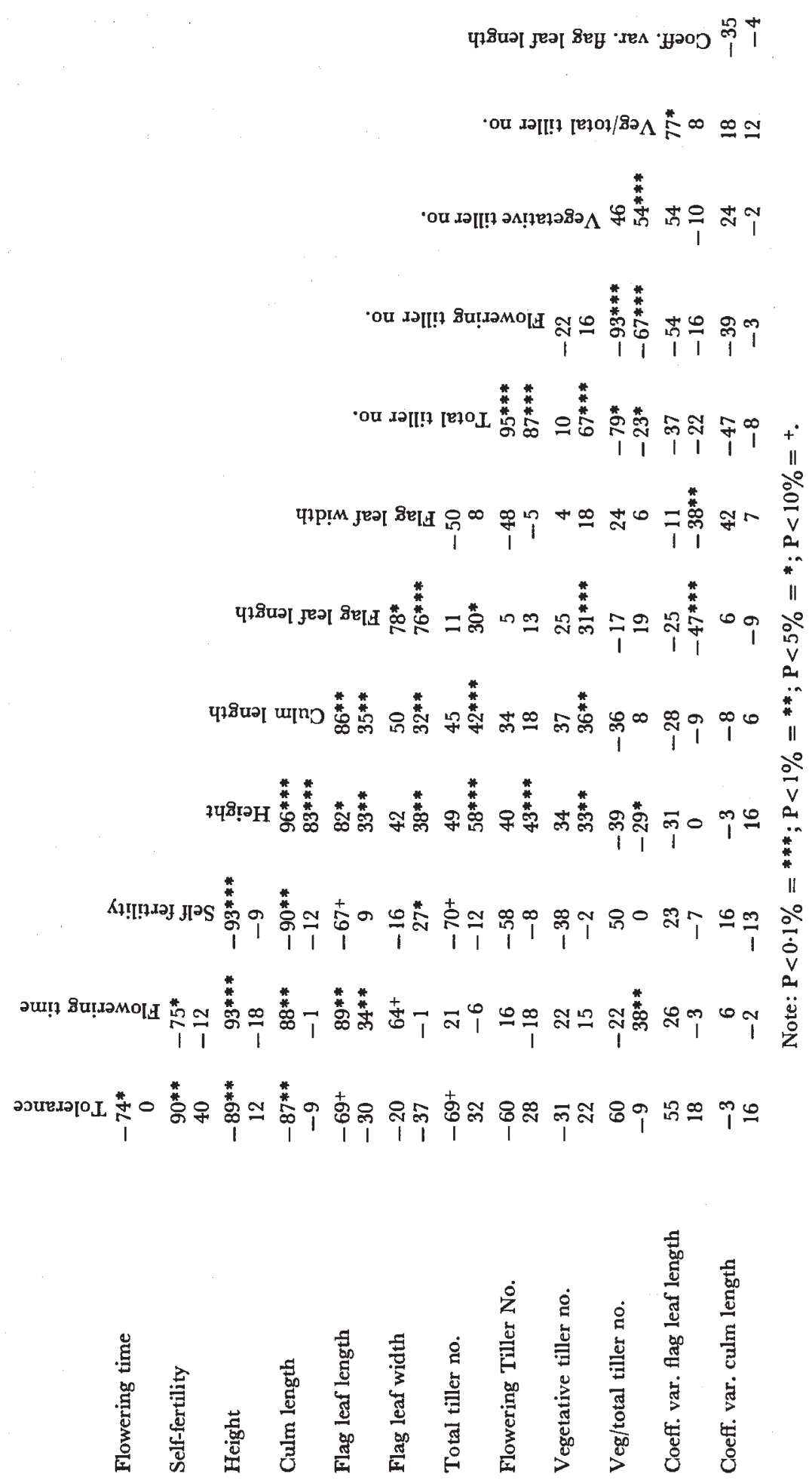


possible to estimate selection pressures from this type of data. For example:

$$
\begin{aligned}
\text { Plant height: Interquartile distance } & =30 \mathrm{ft} . \\
\text { therefore Selection Pressure } & =5.5 \text { per cent. } \\
\text { Flag leaf length: Interquartile distance } & =100 \mathrm{ft} . \\
\text { therefore Selection Pressure } & =0.5 \text { per cent. }
\end{aligned}
$$

For accurate estimates the sampling at habitat boundaries would have to be more intensive than in the present study. For example: site 5 and 6 are 35 feet apart and a cline such as the one for plant height may in reality be much steeper if the plants between site 5 and 6 resemble those in site 6 . An interquartile distance of $10 \mathrm{ft}$ would give a selection pressure of 50 per cent.

\section{(a) Results}

\section{Character correlations}

Two types of correlation between characters were calculated (table 2), namely between site correlation and between individuals within sites. The correlation between sites may arise because of physiological/genetic linkage but it may equally be the result of independent selection for the different characters in the different sites because the environment changes in many respects besides toxicity at the mine boundary. The correlations within sites cannot arise because of this and are therefore likely to be a better indication of physiological/genetic linkage and hence correlated responses.

The within site correlation (based on ten plants per site) was calculated for each site and averaged over the eight sites using the corrected z-transformation to give a mean within site correlation. The following types of situation are found.

(i) Significant within site and between site correlations. These characters cannot be considered to be independent and must be physiologically or genetically linked. In several cases (e.g. total tiller number/flowering or vegetative tiller number, culm length/plant height) the parameters themselves are not independent since one parameter includes another at least in part. In other instances (e.g. flag leaf length/flowering time, height or culm length and flag leaf width) the characters appear to be linked physiologically or genetically. There is here evidence for correlated response to natural selection.

(ii) Significant within site correlations, non-significant between site correlations. These are interesting in that they suggest a physiological or genetic linkage, but that the linkage between them can be broken down by selection. This situation is found in the case of the tiller number characters/the height or culm length characters. Since there are significant differences within and between sites for these characters, it suggests that there is a tendency for taller plants within sites to have more tillers, but that this relation is broken down by selection favouring different relations in the characters between sites. Other examples of such characters are flag leaf width/height or culm length, flag leaf length/total or vegetative tiller number, and vegetative over total tillers/flowering time and vegetative tiller number. A similar relationship is observed with some characters and coefficient of variation of flag leaf length, but since there are no significant differences between sites for this character, significant between site correlations would not be expected. 
(iii) Non-significant correlations within sites, significant correlations between sites. The characters tolerance, flowering time, self fertility, heights or culm length are all correlated with each other between sites but not within sites. They cannot be physiologically or genetically linked. The correlation between sites arises because they all show regular clines.

Flag leaf length is only just correlated ( $P>10$ per cent.) with tolerance and self-fertility confirming that it has a clinal pattern but that it is distinct. Coefficient of variation of flag leaf length is correlated with vegetativeness between sites. This is difficult to explain since the between site differences do not approach significance. This may be a spurious result since out of so many correlations, some are likely to be significant purely by chance.

\section{(b) Discussion}

There is evidence for correlated responses to natural selection on mine habitats. Some of the consistent within and between site correlations that are found can be explained on the grounds that the parameters themselves are not independent, yet other character correlations suggest physiological or genetic linkage. Flag leaf length, in particular, appears to be associated with height or culm length and flowering time, though height or culm length and flowering time are themselves not correlated within sites. This argues in favour of the flag leaf playing an important role in culm development and flowering. Most characters however appear to be independent (within sites) and are probably selected for independently: there is no evidence for a wide range of correlated responses to selection.

A few characters appear to be correlated within sites but not between sites. Selection in different directions in different sites must be operating to break down these correlations. There is therefore evidence (even on this small scale) of restructuring of the associations between characters. Such selection for differing combinations of various characters over such a small area must have profound effects on the genetic structure of the population.

In those cases where there is correlation between sites and not within, the characters all show clinal variation. The fact that many of them show clines of different patterns (which have already been discussed) is itself an indication that there is no physiological or genetical linkage.

Independent selection for a wide range of characters must increase the overall selective mortality of the population and may indeed reach such proportions that it limits the rate of population increase. At present there is no evidence as to whether multiple selection is common or rare in natural populations.

\section{Population variability}

\section{(a) Results}

Both within site variability (for all characters) and within plant variability (for flag leaf length and culm length) was calculated. There are significant differences between individuals within sites for every character studied (table 1), showing that considerable genotypic variation was present in these populations. However, there is no evidence that the tolerant population is more variable, either for between plant variation or within plant variation (fig. 2). A general pattern to emerge however is that characters which show a distinct steep cline, generally have an increased 

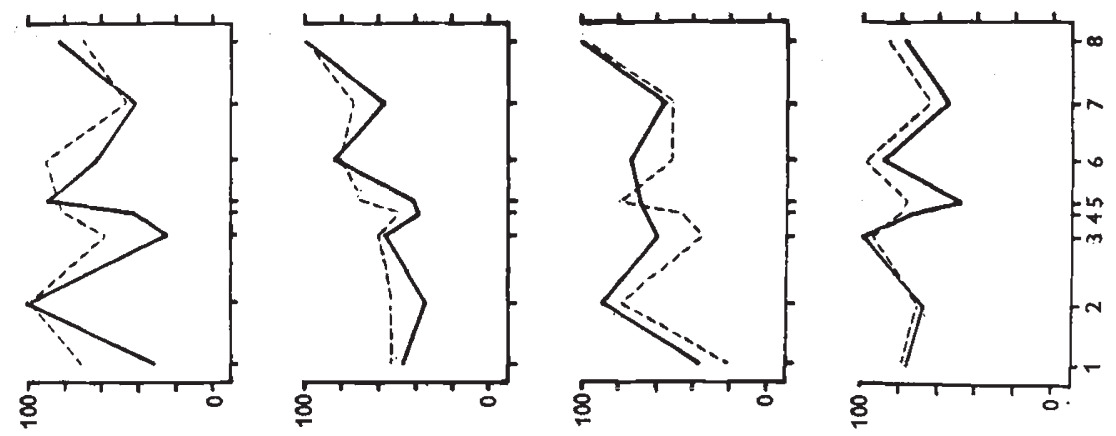

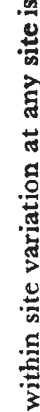

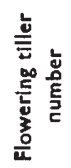

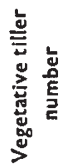

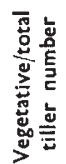
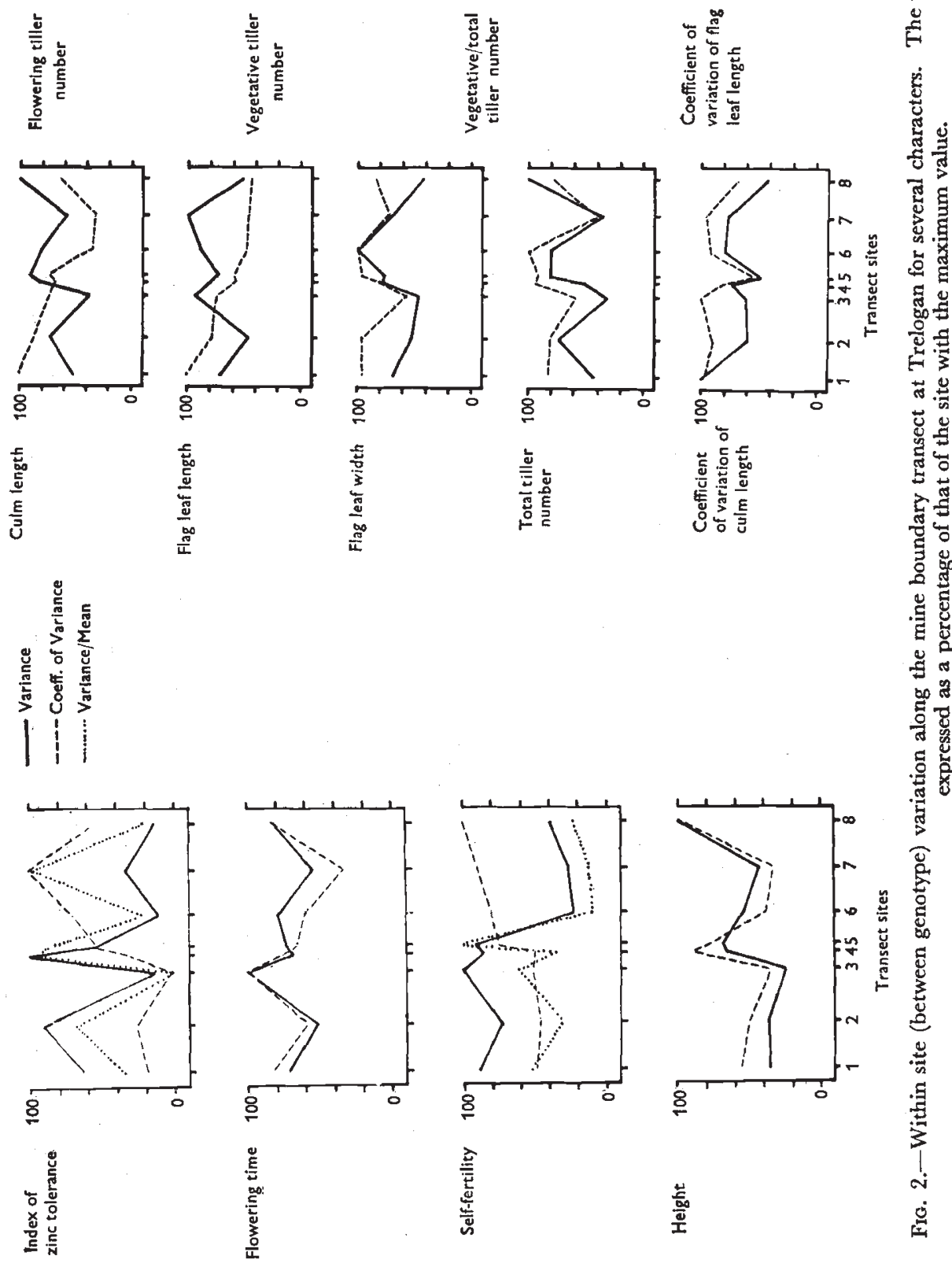
within site variation at the boundary. Where there is no clinal pattern, no trend with regard to variability is observed.

The total variability of each character except tolerance was partitioned into the following types using the variance components of the mean squares:

(i) Environmental variation.

(ii) Genotypic variation.

(a) Between population variation.

(b) Between sites within populations variation.

(c) Between genotypes within sites variation.

The results (fig. 3), in which genotypic variance has been expressed as a percentage of the total, show that the relative importance of genotype and environment in determining the overall population variability differs from character to character. The character of tolerance has been omitted because its measurement did not permit partitioning into a between genotypes within sites component: genetic differences contributed to 86.1 per cent. of the variation in tolerance along the transect.

Apart from flowering time, it is seen that there is a fairly constant amount of variation between genotypes and that it is the variation between sites and between populations which differs for different characters. It can be seen that the larger the between population and between site variation the greater the contribution of the genetic component to the overall variance. Flowering time appears to be an exception in that practically all the variability is genetic and is due to differences between genotypes within sites.

If we consider the transect as a whole population we see that local differentiation (between major habitats or sites within these habitats) contributes considerably to the genetic variability, in spite of the fact that there must be considerable gene exchange between the sites of the transect tending to obscure such differentiation.

\section{(b) Discussion}

There is no evidence in this situation for the hypothesis of Ford (1964) that the mine (expanding) population is more variable than the pasture (stable) population with regard to between plant variation or in the sense of abnormal individuals with a large within plant variance. Although the population is expanding (or has expanded recently), its environment is one which will provide very severe selection. Moreover, on theoretical grounds changes in genetic variability will only be concomitant with changes in population size if the controlling factor is the same for both : selection controls the variability but it is unlikely that the controlling factor of population size is natural selection against extreme variants.

The only consistent pattern to be observed is the increase in the between plant (within site) variability at the boundary. Similar results have been obtained by McNeilly (1968) and Snaydon (see Jain and Bradshaw, 1966). There are three possible reasons for this.

Firstly, there is evidence that the selective processes along a cline will lead to an increased population variability at the boundary. Holgate (1964) gave a formula for the variance of gene frequencies in a local sub-population (site) on a cline, from which one can conclude that the variance will be greater, the more equal the gene frequencies (as will be the case at the boundary) and the greater the selection (as will be the case if the cline is steeper). 
Secondly, at the boundary zone there will be maximum gene exchange, and therefore the populations are likely to be both heterogeneous and heterozygous (Antonovics, 1968 a and 1968b). Thirdly, the sites at the boundary may themselves be heterogeneous and very local adaptation within the site
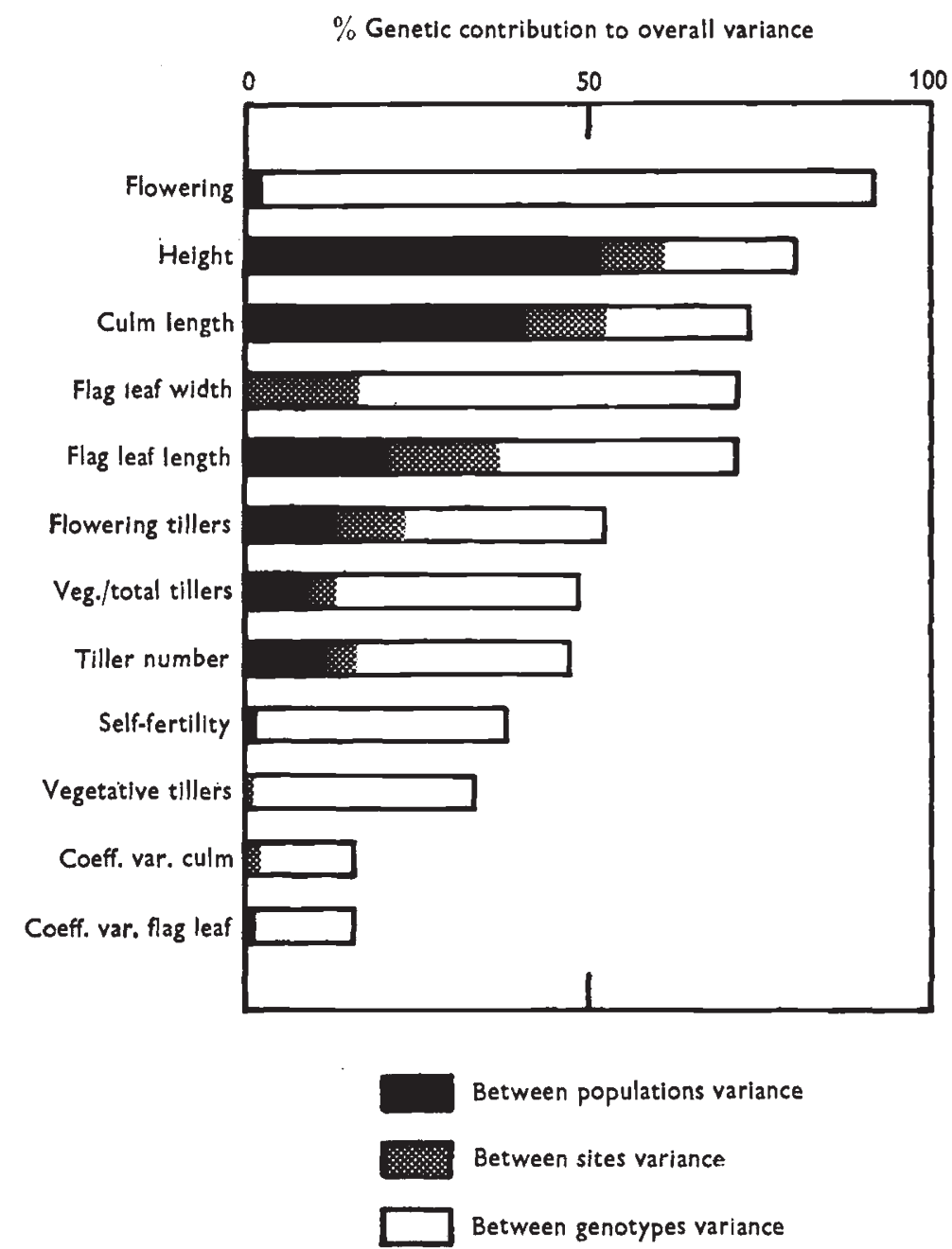

Fic. 3.-The relative contributions of environmental, between genotype between site, and between population variance to the overall variance of different characters along the mine boundary transect at Trelogan. (Values calculated from mean square components.)

may be responsible. It is difficult to distinguish between these alternatives: probably all are responsible for the increased boundary variance and all emphasise the importance of disruptive selection in maintaining population variability.

If we consider the overall variability of the plants along the transect, it is clear that for many characters a large proportion of the genetic variability is made up of either differences between sites or differences between 
populations. Disruptive selection resulting from environmental heterogeneity is maintaining population variability.

To what extent the genetic variation within sites is adaptive and due to selection, or represents a "permissible general level of variation" due to other causes, is impossible to assess. Anthoxanthum odoratum is a perennial and each individual has to be precisely adapted to its local niche if it is to survive for any length of time. However some of this adaptation may be phenotypic, and under the ideal garden conditions of the experimental plants, genotypic differences not normally seen in nature may have become more apparent (Gregor, 1956; Turessen, 1922 and 1925). Again the between plant variability could be the result of expression of genes not normally effective under natural conditions (Cooper, 1953).

Although the variability studied here was morphological, this morphology must have a physiological and biochemical basis. Even for continuously varying characters, such as were studied here, there may be discontinuity at the enzyme level and when enzymes are investigated the differences between them may emerge as polymorphisms: alternative enzyme states may be responsible for continuous variation just as distinct genes are responsible for the same phenomenon. The maintenance of population variability in Anthoxanthum is seen to be the product of disruptive selection in a heterogeneous environment. This suggests that the maintenance of many of the enzyme polymorphisms increasingly reported in recent literature may be due to similar processes.

\section{Conclusion}

The present investigation shows that natural selection at a mine boundary is extremely complex and severe. It accounts for varying clinal patterns and deviations from these patterns. Disruptive selection is occurring at various levels causing large and small scale heterogeneity and maintaining population variability. The selection is multiple and independent for a wide variety of characters and the plant must be adapted in numerous respects in order to survive. Different character combinations are selected for in different sites, leading to breakdown of established associations and creation of new ones, frequently within the space of a few yards. Individual characters have their own patterns of differentiation each quite independent of the other, even when the gene flow operating is the same.

This type of complex selection will have several general consequences. Firstly, adaptation by natural selection can be extremely precise even over minute distances, in the presence of gene flow, and in characters which do not appear to be of primary adaptive significance. Secondly, local selection will lead to and maintain population variability; when studied at an enzyme level this variability may appear discontinuous or polymorphic. At present there is no established technique for measuring population heterogeneity so that different populations can be meaningfully compared. Thirdly, selective mortality will be high both because of gene flow and multiple independent selection. The extent to which the multiple selection leads to a high mortality depends on whether the disadvantageous genes are combined at random or if they are associated: in the mine situation there will be association of genes as a result of their influx from a contrasting habitat, but disassociation because of local adaptation within these habitats. Selection pressures for individual characters can be estimated, but there is no way 
of knowing how to combine the values to estimate the degree of overall selective mortality in the population.

\section{Summary}

1. Plants of Anthoxanthum odoratum L. from eight sites on a transect across the boundary between a lead/zinc mine and pasture soil were grown in an experimental garden and studied with regard to a range of morphological characters.

2. Some characters gave a steep cline at the boundary, others a gradual cline while a third group showed no clear cut clinal pattern.

3. The differing clinal patterns were interpreted to be the result of the same amount of gene flow (between mine and pasture populations) but differing levels of natural selection for the different characters.

4. The clinal patterns could be used to estimate selection coefficients although the sampling was not sufficiently intensive in this experiment to obtain accurate estimates.

5. There was some evidence of correlated response to natural selection: but most of the correlations that were observed within sites could be explained by the parameters themselves not being independent; and those observed between sites could be explained because the characters involved all showed regular clines.

6. Some characters showed strong correlation within sites, but no correlation between sites: independent selection for the characters on the different sites had broken down any physiological or genetical linkage between them.

7. There was no evidence that the plants on the mine population (which was expanding or had recently done so) were more variable than those on the pasture population.

8. The characters showing steep clines showed an increased variability at the boundary sites. This is an expected feature of boundary sites along clines.

9. It was concluded that disruptive selection between mine and pasture populations, and between sites within populations was maintaining population variability.

Acknowledgments.-We wish to thank Mr D. Machin for his help with the statistics.

\section{REFERENCES}

ANTONOvics, J. 1968a. Evolution in closely adjacent plant populations. V. The evolution of self-fertility. Heredity, 23, 219-238.

ANTonovics, J. 1968b. Evolution in closely adjacent plant populations. VI. Manifold effects of gene flow. Heredity, 23, 507-524.

gRADSHAW, A. D. 1959. Population differentiation in Agrostis tenuis Sibth. I. Morphological differentiation. New Phytol., 58, 208-227.

BROKER, W. 1963. Genetisch-physiologische Untersuchungen uber die Zinkvertraglichkeit von Silene inflata Sm. Flora, Jena, 153, 122-156.

COOPER, J. P. 1953. Species and population differences in climatic responses. In Evans, L. T. (Ed.) Environmental Control of Plant Growth. Academic Press, New York, pp. 381403.

COOPER, J. P. 1960. Selection and population structure in Lolium. IV. Correlated response to selection. Heredity, 14, 229-246.

FORD, A. D., AND FORD, E. B. 1930. Fluctuation in numbers and its influence on variation in Melitaea aurinia. Trans. R. ent. Soc. Lond., 78, 345-357.

FORD, E. B. 1964. Ecological Genetics. Methuen. 
GREGOR, J. W. 1956. Genotypic environmental interaction and its bearing on a practical problem of international interest. Proc. Intern. Grassland Congr., 7th, Palmerston, New Zealand, 1956. Pp. 202-211.

GRIFFTTHS, D. J. 1952. The liability of seed crops of perennial ryegrass (Lolium perenne) to contamination by wind borne pollen. F. Agric. Sci. Camb., 40, 19-38.

hALDANE, J. B. s. 1948. The theory of a cline. F. Genet., 48, 277-284.

holgate, P. 1964. Genotype frequencies in a section of a cline. Heredity, 19, 507-509.

JAIN, s. K., AND BRADSHAW, A. D. 1966. Evolutionary divergence among adjacent plant populations. I. The evidence and its theoretical analysis. Heredity, 21, 407-441.

JOWETT, D. 1959. Adaptation of a lead-tolerant population of Agrostis tenuis to low soil fertility. Nature, 184, 43.

JOWETT, D. 1964. Population studies on lead-tolerant Agrostis tenuis. Evolution, 18, 70-80.

KIMURA, M. 1958. A gene-frequency cline determined by selection and migration. Rep. Natn. Inst. Genet., Misima, 9, 84-86.

MATHER, K., AND harRison, B. J. 1949. The manifold effects of selection. Heredity, 3, 1-52 and 131-162.

MCNEILLy, T. 1965. The evolution of copper tolerance in Agrostis tenuis Sibth. Ph.D. Thesis, University of Wales.

MCNEILLY, T. 1968. Evolution in closely adjacent plant populations. III. Agrostis tenuis on a small copper mine. Heredity, 23, 99-108.

MCNEILLY, T., AND ANTONOvics, J. 1968. Evolution in closely adjacent plant populations. IV. Barriers to gene flow. Heredity, 23, 205-218.

SCHWANITZ, P., AND HAHN, H. 1954a. Genetisch-entwicklungsphysiologische Untersuchungen an Galmeipflanzen. I. Pflanzengrosse und Resistenz gegen Zinksulfat bie Viola lutea Hudson, Alsine verna L., und Silene inflata Sm. Z. Bot., 42, 179-190.

SCHWANTTZ, F., AND HAHN, H. 1954 . Genetisch-entwicklungsphysiologische Untersuchungen an Galmeipflanzen. II. Uber Galmeibiotypen bei Linum catharticum L., Campanula rotundifolia L., Plantago lanceolata L., und Rumex acetosa L. Z. Bot., 42, 459-471.

TUREsson, G. 1922. The genotypical response of the plant species to the habitat. Hereditas, 3, 211-350.

TUREsSON, G. 1925. The plant species in relation to habitat and climate. Hereditas, 6, $147-236$.

TURNER, R. G. 1967. Quoted in Antonovics, J., Lovett, J., and Bradshaw, A. D. The evolution of adaptation to nutritional factors in populations of herbage plants. Isotopes in Plant Nutrition and Physiology, I.A.E.A., Vienna. Pp. 549-567. 